\title{
Nanodomains of pyrochlore formed by Ti ion implantation in yttria-stabilized zirconia
}

\author{
S. Zhu, X. T. Zu, ${ }^{\text {a) }}$ L. M. Wang, ${ }^{\text {b) }}$ and R. C. Ewing \\ Department of Nuclear Engineering and Radiological Sciences, University of Michigan, Ann Arbor, \\ Michigan 48109-2104
}

(Received 28 February 2002; accepted for publication 4 April 2002)

\begin{abstract}
The microstructural evolution of a single crystal of yttria-stabilized zirconia (YSZ) implanted with Ti has been studied by cross-sectional transmission electron microscopy (TEM). The implantation of $180 \mathrm{keV}$ Ti ions to a dose of $1 \times 10^{17} \mathrm{ions} / \mathrm{cm}^{2}$ was completed at room temperature. After annealing at $1100{ }^{\circ} \mathrm{C}$ in an $\mathrm{Ar}$ atmosphere for $2 \mathrm{~h}$, a phase transition from the fluorite structure of $\mathrm{ZrO}_{2}$ to an isometric pyrochlore structure-type, $\mathrm{A}_{2} \mathrm{~B}_{2} \mathrm{O}_{7}$, occurred due to cation ordering. High-resolution TEM revealed nanodomains of pyrochlore, $\mathrm{Y}_{2}\left(\mathrm{Ti}_{x} \mathrm{Zr}_{1-x}\right)_{2} \mathrm{O}_{7}$, with $a \cong 10.24 \pm 0.05$ $\AA$. The nanodomains of the pyrochlore phase, embedded within the YSZ fluorite substrate, occurred in a depth range from 45 to $105 \mathrm{~nm}$ below the surface, which corresponds to Ti concentrations from $\sim 10$ to $\sim 15$ at. $\%$. The nanoscale pyrochlore precipitates and the YSZ matrix have a completely coherent orientation. (C) 2002 American Institute of Physics. [DOI: 10.1063/1.1482784]
\end{abstract}

Fluorite and pyrochlore are two important isometric structure-types. Yttria stabilized zirconia (YSZ), with the fluorite structure, has been studied as an inert matrix fuel for "burning" plutonium that originates from the dismantlement of nuclear weapons or the reprocessing of nuclear fuel from commercial power reactors. ${ }^{1,2}$ Pyrochlore with the general formula of $\mathrm{A}_{2} \mathrm{~B}_{2} \mathrm{O}_{7}$ ( $\mathrm{A}$ and $\mathrm{B}$ are metal elements) is isometric and an important candidate material for the immobilization of plutonium and other actinides. ${ }^{3,4}$ Both of these structurally related materials are also important fast ion conductors that can be used as a component in oxygen sensors, oxygen pumps, and solid oxide fuel cells. ${ }^{5,6}$ Pyrochlore is a derivative of the fluorite structure. ${ }^{7}$ Wang et al. have reported that pyrochlore compositions, such as $\mathrm{Gd}_{2} \mathrm{Ti}_{2} \mathrm{O}_{7}$ and $\mathrm{Y}_{2} \mathrm{Zr}_{2} \mathrm{O}_{7}$, undergo a pyrochlore-to-fluorite structure transformation at different temperatures with the irradiation of $\mathrm{Kr}^{+}$ions at the early stage of irradiation. ${ }^{8,9}$ A similar result has also been confirmed by Smith et al. and Begg et al. using x-ray diffraction and Raman spectroscopy. ${ }^{10,11}$ This structural transition is a radiation-induced orderdisorder transformation. ${ }^{8-11}$ However, the reverse process has not been observed. In this letter, we report the transformation of the fluorite-structure of $\mathrm{ZrO}_{2}$ to the ordered structure of pyrochlore by ion implantation.

A well-polished YSZ $\left(9.5 \mathrm{~mol} \% \mathrm{Y}_{2} \mathrm{O}_{3}\right)$ single crystal wafer of (001) orientation was implanted with $180 \mathrm{keV} \mathrm{Ti}^{+}$ ions to a dose of $1.0 \times 10^{17} / \mathrm{cm}^{2}$. The ion implantation was conducted at room temperature using a Varian 200 ion implanter. A subsequent thermal anneal was completed at $1100{ }^{\circ} \mathrm{C}$ in an $\mathrm{Ar}$ atmosphere for $2 \mathrm{~h}$. $\mathrm{The} \mathrm{Ti}^{+}$ion distribution and damage profile in the YSZ matrix was calculated using SRIM 2000. ${ }^{12}$ A displacement energy of $40 \mathrm{eV}$ was used for every type of atom in YSZ. ${ }^{13}$ According to the cal-

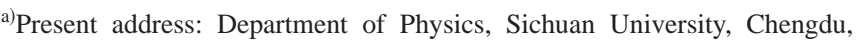
610064, People's Republic of China.

b) Author to whom correspondence should be addressed; electronic mail: lmwang@umich.edu
}

culation, this irradiation causes a maximum damage level of 120 displacements per atom at the depth of $45 \mathrm{~nm}$ and the $\mathrm{Ti}^{+}$ion concentration has a maximum of 15 at.\% at the depth of $85 \mathrm{~nm}$ (Fig. 1). Cross-sectional transmission electron microscopy (TEM) analysis was completed using a JEM 2010F electron microscope in the Electron Microbeam Analysis Laboratory (EMAL) of the University of Michigan.

A low magnification TEM image [Fig. 2(a)] shows the cross-sectional microstructure of the YSZ sample after $\mathrm{Ti}^{+}$ implantation, followed by thermal treatment. The strain contrast in the region from a depth of $\sim 45-\sim 105 \mathrm{~nm}$ below the surface corresponds to the defects formed due to implantation. The selected area electron diffraction (SAD) pattern in the [110] direction showed a sharp $g \pm 1 / 2\langle 111\rangle$ type satellite reflection, ${ }^{14}$ where $g$ corresponds to the strong Bragg peak of the underlying fluorite structure, as shown in the Fig. 2(c). In the near surface area and the area beyond the end-of-range of the implanted ions, the satellite reflections are not evident [Fig. 2(b)]. By using high-resolution electron microscopy

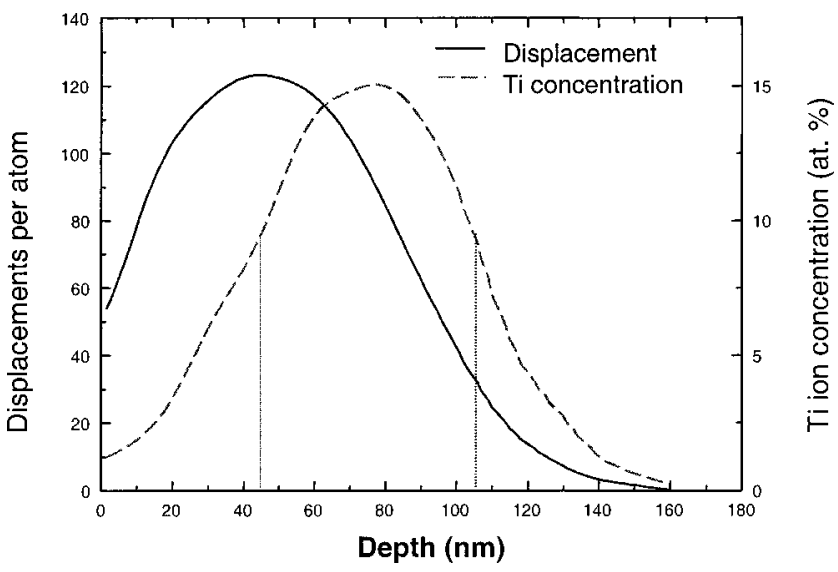

FIG. 1. Depth profile of displacement damage and implanted $\mathrm{Ti}^{+}$ion concentration with a dose of $1 \times 10^{17} \mathrm{Ti} / \mathrm{cm}^{2}$ in YSZ calculated by SRIM 2000 with an $E_{d}$ of $40 \mathrm{eV}$. The two dashed vertical lines define the peak Tiimplantation region. 


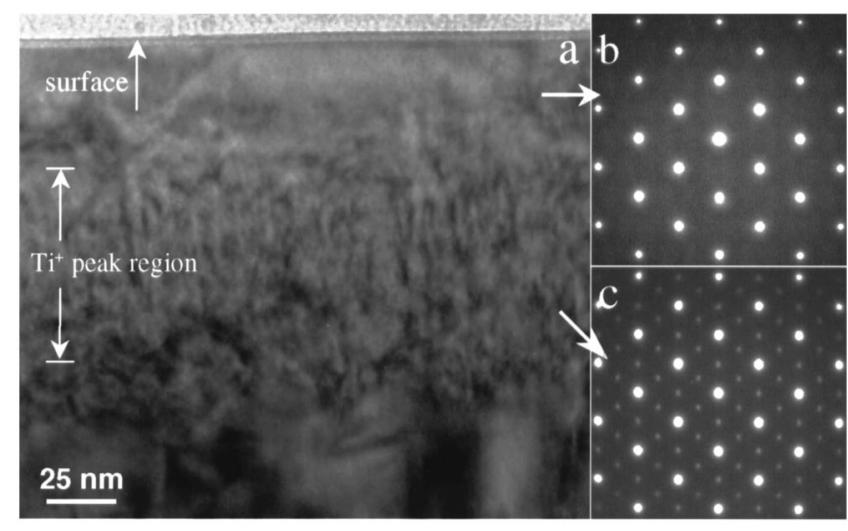

FIG. 2. (a) Bright-field cross-sectional TEM micrograph showing the depth dependent microstructure of YSZ after $180 \mathrm{keV}$ Ti implantation to 1 $\times 10^{17}$ ions $/ \mathrm{cm}^{2}$ at room temperature; (b) SAD pattern of [110] zone from the surface area in showing YSZ structure; (c) SAD pattern of [110] from the implantation peak revealing superlattice spots corresponding to the cation ordering in the pyrochlore structure.

(HRTEM), a phase transition at a depth from $\sim 45$ to $\sim 105$ $\mathrm{nm}$ of the YSZ matrix (the area where the satellite reflections appeared in the SAD pattern) was observed [Fig. 3(a)]. These satellite reflections [in Fig. 2(c)] are from discontinuous nanoscale domains of a pyrochlore phase with a superlattice structure, $\mathrm{Y}_{2}\left(\mathrm{Ti}_{x} \mathrm{Zr}_{1-x}\right)_{2} \mathrm{O}_{7}$, with $a \cong 10.24 \pm 0.05 \AA$. Because the lattice constant of the pyrochlore phase is almost twice that of the YSZ $(a \cong 5.16 \AA)$, the intense reflections in the SAD pattern of $\mathrm{Y}_{2}\left(\mathrm{Ti}_{x} \mathrm{Zr}_{1-x}\right)_{2} \mathrm{O}_{7}$ overlapped with the spots from YSZ. A Fourier transform of the lattice images corresponding to the two different nanodomains outlined in Fig. 3(a) also confirmed the formation of the pyrochlore phase [Figs. 3(b) and 3(c)]. As shown in Fig. 3(a), the $d$ spacing of the (200) lattice fringe of pyrochlore is $0.513 \mathrm{~nm}$, while it is $0.258 \mathrm{~nm}$ for the fluorite structure, almost one half that of the pyrochlore structure. The orientational relationship between the YSZ host and the pyrochlore precipitates is completely coherent, i.e., $[110]_{\mathrm{YsZ}} / /[110]_{\mathrm{P}}$, and $(1 \overline{1} 1)_{\mathrm{YsZ}} / /(1 \overline{1} 1)_{\mathrm{P}}$. The isolated $\mathrm{Y}_{2}\left(\mathrm{Ti}_{x} \mathrm{Zr}_{1-x}\right)_{2} \mathrm{O}_{7}$ nanodomains were approximately $20-25 \mathrm{vol} \%$ in the Ti concentration peak region shown in Fig. 2(a). Energy dispersive $\mathrm{x}$-ray spectroscopy analysis with a $0.5 \mathrm{~nm}$ beam spot has

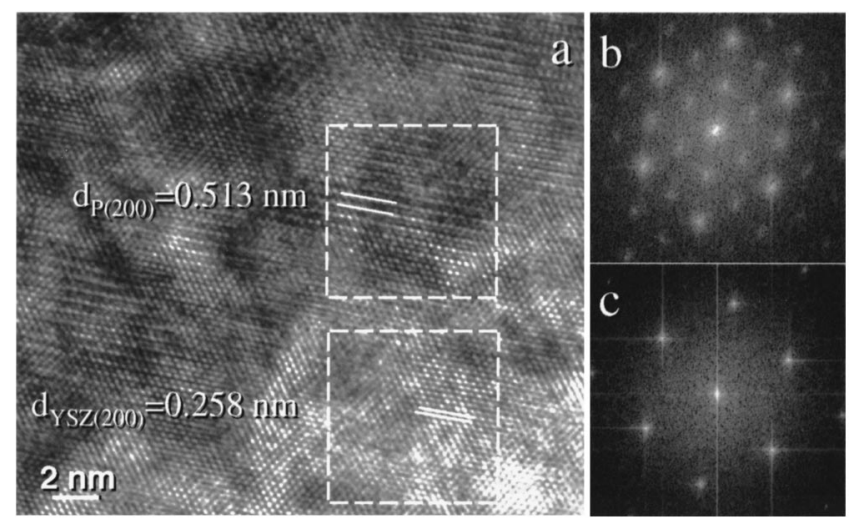

FIG. 3. High-resolution TEM micrograph from the peak implantation depth of the samples in Fig. 2, (a) with corresponding Fourier transformation images showing the formation of discontinuous nanodomains of pyrochlore $\mathrm{Y}_{2}\left(\mathrm{Zr}_{x} \mathrm{Ti}_{1-x}\right)_{2} \mathrm{O}_{7}$ with superlattice (b) and fluorite structure (c). indicated a strong $\mathrm{Y}$ enrichment in the nanodomains with the superlattice structure.

Because of the formation of nanodomains of $\mathrm{Y}_{2}\left(\mathrm{Ti}_{x} \mathrm{Zr}_{1-x}\right)_{2} \mathrm{O}_{7}$ phase, the segregation of $\mathrm{Y}$ is inevitable. The enrichment of $\mathrm{Y}$ in the $\mathrm{Y}_{2}\left(\mathrm{Ti}_{x} \mathrm{Zr}_{1-x}\right)_{2} \mathrm{O}_{7}$ phase may result in a lower amount of $\mathrm{Y}$ in the surrounding fluorite structure. However, the remaining amount of $\mathrm{Y}$ in the surrounding fluorite structure can still stabilize the fluorite structure. The monoclinic $\mathrm{ZrO}_{2}$ phase, a distorted fluorite structure $(a=0.5146 \mathrm{~nm}, \quad b=0.5213 \mathrm{~nm}, \quad c=0.5311 \mathrm{~nm}, \quad$ and $\beta=99.2^{\circ}$ ), which will be formed in the entirely Y-depleted zones due to the segregation of $\mathrm{Y}$, has not been observed in this experiment.

The formation of the pyrochlore phase can be explained to be the result of ordering of cations in the fluorite structure. Ion beam implantation produces a high density of defects due to atomic collisions in the host materials. The local stoichiometric composition may change due to the irradiationinduced segregation and the presence of implanted ions. Defect accumulation and ion mixing increase the free energy of the host material. ${ }^{15}$ Although relaxation towards equilibrium occurs during implantation, the period for relaxation is too short $\left(10^{-12}-10^{-9} \mathrm{~s}\right),{ }^{16}$ and the mixture of the matrix and implanted ion cannot reach an equilibrium state. The structure is thus a thermodynamically unstable defect structure after implantation. Thermal annealing reduces the density of defect clusters and causes redistribution of implanted ions to form a microstructure that is closer to thermodynamic equilibrium. In the case of $\mathrm{Ti}$ implanted YSZ, this redistribution involves ordering of cations with $\mathrm{Y}$ on the A site and $\mathrm{Ti} / \mathrm{Zr}$ on $\mathrm{B}$ site to form the $\mathrm{A}_{2} \mathrm{~B}_{2} \mathrm{O}_{7}$ pyrochlore domains.

Pyrochlore, $\mathrm{A}_{2}^{3+} \mathrm{B}_{2}^{4+} \mathrm{O}_{7}$, is a derivative of the fluorite structure, but with one-eighth fewer anions and two types of cation sites. The A-site cation is surrounded by eight oxygen anions that occupy the $48 f$ sites, and B-site cation is coordinated to six oxygen anions. ${ }^{7}$ In other words, there are two unique oxygen sites in the pyrochlore structure. Six oxygen anions occupy the $48 f$ sites, surrounded by two A-site cations and two B-site cations, while the seventh oxygen atom occupies the $8 b$ site and is surrounded by four A-site cations. The remaining unoccupied $8 a$ sites are surrounded by B-site cations. In the defect fluorite structure $(\mathrm{AB}) \mathrm{O}_{2}$, there is no difference in cation coordination. Every cation is coordinated to eight oxygen anions and every oxygen is coordinated by four randomly distributed cations. Furthermore, the relative stability of both structures is governed by the ionic radius ratio of the A- and B-site cations $\left(r_{\mathrm{A}} / r_{\mathrm{B}}\right)$. The ratio $\left(r_{\mathrm{A}} / r_{\mathrm{B}}\right)$ of a pyrochlore phase is generally in the range $1.10-1.24 .{ }^{8} \mathrm{~A}$ smaller ratio favors the fluorite structure. The effective ionic radii of $\mathrm{Y}^{3+}$ and $\mathrm{Zr}^{4+}$ with eight coordination are 1.015 and $0.84 \AA$, respectively. ${ }^{17}$ The effective ionic radius of $\mathrm{Ti}^{4+}$ with six coordination is $0.605 \AA .{ }^{17}$ The partial substitution of $\mathrm{Zr}^{4+}$ by $\mathrm{Ti}^{4+}$ resulted in an increase in the average ratio of $r_{\mathrm{A}}$ and $r_{\mathrm{B}}$, making the pyrochlore structure stable. This is consistent with previously reported structural transformations in highly doped Ti-YSZ investigated by Raman spectra. ${ }^{18}$ Moreover, $\mathrm{Ti}^{4+}$ usually prefers six oxygen coordination. ${ }^{19}$ This preference of $\mathrm{Ti}^{4+}$ for six oxygen coordination makes it prefer the $\mathrm{B}$ site along with $\mathrm{Zr}^{4+}$, while $\mathrm{Y}^{3+}$ is in the eight-coordination A-site. This leads to cation 
ordering and the transition of the Ti-implanted defect fluorite ( $\mathrm{YZr}) \mathrm{O}_{2}$ to a pyrochlore $\mathrm{Y}_{2}\left(\mathrm{Ti}_{x} \mathrm{Zr}_{1-x}\right)_{2} \mathrm{O}_{7}$.

In summary, the formation of nanodomains of the pyrochlore phase $\mathrm{Y}_{2}\left(\mathrm{Zr}_{x} \mathrm{Ti}_{1-x}\right)_{2} \mathrm{O}_{7}$ in Ti-ion implanted YSZ has been observed in Ti-ion implanted YSZ by TEM and HRTEM. The formation of the pyrochlore phase is the result of Y segregation and subsequent cation ordering that leads to the formation of pyrochlore structure.

The authors thank V. H. Rotberg of the Michigan Ion Beam Laboratory for surface modification and analysis for conducting the $\mathrm{Ti}^{+}$ion implantation. The TEM analysis was conducted in Electron Microbeam Analysis Laboratory at the University of Michigan, and we acknowledge the support of NSF Award No. DMR-9371177. This work is supported by US Department of Energy under Grant No. DE-FG0799ID13767.

${ }^{1}$ V. M. Oversby, C. C. McPheeters, C. Degueldre, and J.-M. Paratte, J. Nucl. Mater. 245, 17 (1997).

${ }^{2}$ L. M. Wang, S. X. Wang, and R. C. Ewing, Philos. Mag. Lett. 80, 341 (2000).

${ }^{3}$ R. C. Ewing, W. J. Weber, and W. Lutze, in Disposal of Weapon Plutonium, edited by E. R. Merz and C. E. Walter (Kluwer Academic, Boston, 1996), pp. 65-83.
${ }^{4}$ S. X. Wang, L. M. Wang, R. C. Ewing, G. S. Was, and G. R. Lumpkin, Nucl. Instrum. Methods Phys. Res. B 148, 704 (1999).

${ }^{5}$ A. M. Azad, S. Larose, and S. A. Akbar, J. Mater. Sci. 29, 4135 (1994).

${ }^{6}$ M. A. Subramanian, G. Aravamudan, and G. V. Subba Rao, Prog. Solid State Chem. 15, 55 (1983).

${ }^{7}$ B. C. Chakoumakos, J. Solid State Chem. 53, 120 (1984).

${ }^{8}$ S. X. Wang, B. D. Begg, L. M. Wang, R. C. Ewing, W. J. Weber, and K. V. Govidan Kutty, J. Mater. Res. 14, 4470 (1999).

${ }^{9}$ J. Lian, L. M. Wang, S. X. Wang, J. Chen, L. A. Boatner, and R. C. Ewing, Phys. Rev. Lett. 8714, 5901 (2001).

${ }^{10}$ K. L. Smith, N. J. Zaluzec, and G. R. Lumpkin, J. Nucl. Mater. 250, 36 (1997).

${ }^{11}$ B. D. Begg, N. J. Hess, D. E. McCready, S. Thevuthasan, and W. J. Weber, J. Nucl. Mater. 289, 188 (2001).

${ }^{12}$ J. F. Zirgler, The Stopping and Range of Ions in Matter IBM-Research, Yorktown, NY, 2000.

${ }^{13}$ S. J. Zinkle and C. Kinoshita, J. Nucl. Mater. 251, 200 (1997).

${ }^{14}$ Y. Tabira, R. L. Withers, J. C. Barry, and L. Elcoro, J. Solid State Chem. 159, 121 (2001).

${ }^{15}$ M. Nastasi and J. W. Mayer, Mater. Sci. Rep. 6, 1 (1991).

${ }^{16}$ M. T. Robinson, J. Nucl. Mater. 216, 1 (1994).

${ }^{17}$ R. D. Shannon and C. T. Prewitt, Acta Crystallogr., Sect. B: Struct. Crystallogr. Cryst. Chem. B25, 9256 (1969).

${ }^{18}$ M. Glerup, O. F. Nielsen, and F. W. Poulsen, J. Solid State Chem. 160, 25 (2000).

${ }^{19}$ L. S. M. Traqueia, T. Pagnier, and F. M. B. Marques, J. Eur. Ceram. Soc. 17, 1019 (1997). 